\title{
Biodiversidade e estrutura da comunidade zooplanctônica na Sub- bacia Hidrográfica do Rio Poxim, Sergipe, Brasil
}

\author{
(http://dx.doi.org/10.4136/ambi-agua.194)
}

\author{
Ana Paula Sousa Pereira'; Anderson Nascimento do Vasco²; Fábio Brandão Britto; \\ Arisvaldo Vieira Méllo Júnior ${ }^{4}$; Eliane Maria de Souza Nogueira ${ }^{5}$ \\ ${ }^{1}$ Programa de Pós-Graduação em Agroecossistemas - NEREN, Universidade de Federal de Sergipe (UFS). \\ e-mail: bioanap_va@hotmail.com, \\ ${ }^{2}$ Doutorando em Desenvolvimento e Meio Ambiente (Prodema), Universidade Federal de Sergipe (UFS) \\ e-mail: anderovasco@yahoo.com.br, \\ ${ }^{3}$ Programa de Pós-Graduação em Agroecossitema, Universidade Federal de Sergipe (UFS) \\ e-mail: brandaobritto@hotmail.com, \\ ${ }^{4}$ Departamento de Engenharia Hidráulica da Universidade de São Paulo (USP) \\ e-mail: arimello@gmail.com, \\ ${ }^{5}$ Departamento de Educação da Universidade do Estado da Bahia (UNEB), Campus VIII \\ e-mail: emsnogueira@yahoo.com.br
}

\section{RESUMO}

O zooplâncton de ambientes aquáticos continentais é constituído na sua maioria por protozoários, rotíferos, cladóceros e copépodos, os quais desempenham papel importante na cadeia alimentar, transferindo massa e energia de produtores primários para níveis tróficos superiores. Este trabalho foi elaborado com o objetivo de contribuir para o conhecimento da biodiversidade zooplanctônica que ocorre na Sub-bacia Hidrográfica do Rio Poxim. As amostras de água foram tomadas, mensalmente, em quatro estações de coleta, distribuídas ao longo da sub-bacia, no período de agosto de 2009 a julho de 2010. Para obtenção da comunidade de zooplâncton, foram filtrados $100 \mathrm{~L}$ da água numa tela de nylon, com aberturas de malha de $50 \mu \mathrm{m}$. Foram identificados 72 táxons distribuídos nas seguintes categorias taxonômicas Rotifera, Protozoa, Porifera, Nematoda, Anellida, Cladocera, Copepoda, Ostracoda, Isopoda e Insecta. No tocante a riqueza de espécies, o filo Rotífera seguido dos Protoctistas foram os mais relevantes com quarenta e quinze táxons, respectivamente. Os táxons de maior representatividade numérica foram Arcella vulgaris, Notholca sp., Rotaria $s p$. e nematóides. No tocante ao índice de diversidade, a comunidade foi caracterizada por baixa diversidade, no entanto os táxons se distribuíram uniformemente em todos os pontos de monitoramento.

Palavras-chave: Comunidade zooplanctônica; diversidade; bioindicadores.

\section{Biodiversity and community structure of zooplankton in the Sub-basin of Rio Poxim, Sergipe, Brazil}

\begin{abstract}
The zooplankton of aquatic environments is composed mostly of protozoans, rotifers, cladocerans and copepods, which play an important role in the food chain, transferring mass and energy from primary producers to higher trophic levels. This work was prepared with the objective of contributing to the knowledge of zooplankton biodiversity that occurs in the Subbasin of Rio Poxim. Water samples were taken at monthly intervals at four sampling stations located along the sub-basin in the period August 2009 to July 2010. To obtain the
\end{abstract}


PEREIRA, A. P. S.; VASCO, A. N. do; BRITTO, F. B.; MÉllo JÚNIOR, A. V.; NOGUEIRA, E. M. de S. Biodiversidade e estrutura da comunidade zooplanctônica na Sub-bacia Hidrográfica do Rio Poxim, Sergipe, Brasil.. Ambi-Agua, Taubaté, v. 6, n. 2, p. 191-205, 2011. (doi:10.4136/ambi-agua.194)

zooplankton community, $100 \mathrm{~L}$ of water were filtered on nylon net with an aperture of $50 \mu \mathrm{m}$. Were identified 72 taxa distributed in the following taxonomic categories Rotifera, Protozoa, Porifera, Nematoda, Anellida, Cladocera, Copepoda, Ostracoda, Isopoda and Insecta. In terms of species richness, the phylum Rotifera followed by the Protoctista were the most relevant with forty and fifteen taxa, respectively. The most representative taxa in numerical terms were Arcella vulgaris, Notholca sp. Rotary sp. and nematodes. Regarding the community diversity index, the community was characterized as low diversity, but the taxa were distributed evenly in all monitoring points.

Keywords: Zooplankton community; diversity; bioindicator.

\section{INTRODUÇÃO}

O zooplâncton de ambientes aquáticos continentais é constituído na sua maioria por protozoários, rotíferos, cladóceros e copépodos, os quais desempenham papel importante na cadeia alimentar, transferindo massa e energia de produtores primários para níveis tróficos superiores.

Os protozoários são responsáveis pela transferência da biomassa bacteriana para os metazoários zooplanctônicos (Gilron e Lynn, 1997; Esteves, 1998). O conhecimento das interações entre protozoários e metazoários zooplanctônicos e seu papel em determinar o destino da produção do fitoplâncton e bactérias são essenciais para o entendimento do fluxo de energia nessas cadeias alimentares (Sanders e Wickham, 1993). Em relação aos rotíferos, sua importância no plâncton é atribuída à alta taxa reprodutiva e conversão da produção primária, de forma que esta possa ser utilizada pelos consumidores secundários, chegando a produzir até 30\% da biomassa total do plâncton (Nogrady, 1993; Andreoli e Carneiro, 2005).

Entre os microcrustáceos, os cladóceros apresentam grande número de espécies, principalmente em regiões litorâneas de lagos e reservatórios, vivendo associados à macrófitas, alimentado-se basicamente de algas e perifíton (Sipaúba-Tavares e Rocha, 2001; Serafim Jr., 2002). Por outro lado, os copépodos apresentam elevado grau de endemismo com a distribuição geográfica muito restrita por serem mais sensíveis às alterações das variáveis ambientais (Matsumura-Tundisi e Tundisi, 2003).

Esses grupos zooplanctônicos apresentam diferentes estratégias reprodutivas (de uma simples fissão a reprodução sexuada), as quais irão refletir no tamanho de suas populações e na disponibilidade de recursos para estas. Os rotíferos e cladóceros, em condições adequadas, apresentam reprodução partenogenética em intervalos frequentes. A reprodução sexuada para esses dois grupos está confinada a raros períodos, em resposta às condições adversas do ambiente produzindo ovos de resistência. Nos copépodos, a reprodução é sexuada e seu crescimento populacional é mais lento quando comparados aos outros grupos (SipaúbaTavares e Rocha, 2001). Os ovos são mantidos presos ao abdome, em um ou mais sacos ovígeros. Em alguns gêneros a produção de ovos de resistência pode ocorrer, passando longos períodos no sedimento (Esteves, 1998).

O curto período de vida e a elevada taxa de renovação fazem com que esses organismos respondam rapidamente às perturbações que alteram as características físicas, químicas $\mathrm{e}$ biológicas da água (Serafim Jr., 2002). Entre os fatores ambientais que mais interferem na composição e abundância do zooplâncton pode-se destacar a temperatura, a competição intra e interespecífica, a predação e a qualidade e disponibilidade de alimentos (Sampaio et al., 2002)

O hábito alimentar dos organismos zooplanctônicos pode-se diferenciar de acordo com o tipo e a obtenção do alimento. Os protozoários são hábeis para ingerir bactérias e cianobactérias, e são eles mesmos que, por seu tamanho reduzido, são altamente suscetíveis a 
PEREIRA, A. P. S.; VASCO, A. N. do; BRITTO, F. B.; MÉllo JÚNIOR, A. V.; NOGUEIRA, E. M. de S. Biodiversidade e estrutura da comunidade zooplanctônica na Sub-bacia Hidrográfica do Rio Poxim, Sergipe, Brasil.. Ambi-Agua, Taubaté, v. 6, n. 2, p. 191-205, 2011. (doi:10.4136/ambi-agua.194)

predação por metazoários zooplânctonicos (Sanders e Wickham, 1993). Os rotíferos alimentam-se tanto de algas como detritos e bactérias por meio de vibrações da coroa ciliada. Uma ampla variedade de predadores é observada entre esse grupo, entretanto somente Asplanchna e, em menor grau, Ploesoma, são conhecidos como importantes predadores de pequenos rotíferos (Stemberg e Gilbert, 1987).

Os cladóceros são excelentes filtradores e sua alimentação básica se constitui de fitoplâncton e detritos. A taxa de filtração está diretamente relacionada ao tamanho do animal e partícula a ser ingerida. Os itens alimentares de maior valor nutricional, como algas vivas, são melhor aproveitadas (Esteves, 1998). Os copépodos podem apresentar três tipos de hábito alimentar, dependendo da estrutura do aparelho bucal: filtrador, carnívoro e raptorial. Esses organismos são filtradores mais seletivos, podendo discriminar seu alimento e decidir qual é o mais palatável (Lampert, 1987). Para os copépodos calanóides, o nanofitoplâncton é a principal fonte de energia e as bactérias e os detritos podem funcionar como fonte adicional e, às vezes, alternativa (Sipaúba-Tavares e Rocha, 2001).

A atividade alimentar do zooplâncton exerce grande influência na proliferação do próprio fitoplâncton e bacterioplâncton, pelos efeitos simultâneos de herbivoria e reciclagem de nutrientes. As interações entre os níveis tróficos podem modular os impactos das adições de nutrientes. Como, por exemplo, pode ser citada a excreção do fósforo pelo zooplâncton, um dos principais mecanismos de regeneração desse elemento químico na coluna de água, em adição à ação da fosfatase (Andreoli e Carneiro, 2005).

É comum ocorrer mudanças sobre alguns atributos da comunidade zooplanctônica em associação as alterações provocadas pelo homem, tais como a riqueza de espécies, a equitabilidade, a dominância, suas densidades, bem como a exclusão de determinadas espécies e um elevado crescimento populacional de outras (Pinto-Coelho et al., 1999).

Assim considerando os pressupostos de que a comunidade zooplanctônica é funcionalmente importante em ecossistemas aquáticos e que o uso e ocupação do solo refletem sobre alguns atributos dessa comunidade, o objetivo do presente estudo foi contribuir para o conhecimento da biodiversidade e da estrutura espacial e temporal do zooplâncton que ocorre na Sub-bacia do Rio Poxim no Estado de Sergipe.

\section{MATERIAL E MÉTODOS}

A Sub-bacia Hidrográfica do Rio Poxim está situada entre as coordenadas geográficas $11^{\circ} 01^{\prime}$ e $10^{\circ} 47^{\prime}$ de latitude sul e $37^{\circ} 01^{\prime}$ e $37^{\circ} 24^{\prime}$ de longitude oeste, faz parte da bacia do rio Sergipe e está inserida na região metropolitana da Grande Aracaju. Dos nove municípios que compõem a região metropolitana de Aracaju, cinco deles têm seu território total ou parcialmente dentro da área de abrangência da sub-bacia hidrográfica: Aracaju, São Cristóvão, Nossa Senhora do Socorro, Laranjeiras e Itaporanga D’Ajuda. A única exceção é o município de Areia Branca, que tem parte de seu território dentro da área da sub-bacia hidrográfica do rio Poxim, mas não integra a supracitada região metropolitana (Sergipe, 2004).

As amostras de água foram coletadas em quatro pontos de monitoramento distribuídos ao longo da Sub-bacia Hidrográfica. A localização dos pontos de amostragem é indicada na Figura 1. O ponto P1 está situado no afluente rio Poxim-Mirim, o ponto P2, no afluente rio Poxim-Açu, os pontos P3 e P4 estão localizados no leito principal do rio Poxim, o P3 está localizado próximo à confluência dos rios Poxim-Mirim e Poxim-Açu e o P4 localiza-se na captação para abastecimento público da Companhia de Saneamento de Sergipe - DESO. 
PEREIRA, A. P. S.; VASCO, A. N. do; BRITTO, F. B.; MÉllo JÚNIOR, A. V.; NOGUEIRA, E. M. de S. Biodiversidade e estrutura da comunidade zooplanctônica na Sub-bacia Hidrográfica do Rio Poxim, Sergipe, Brasil.. Ambi-Agua, Taubaté, v. 6, n. 2, p. 191-205, 2011. (doi:10.4136/ambi-agua.194)

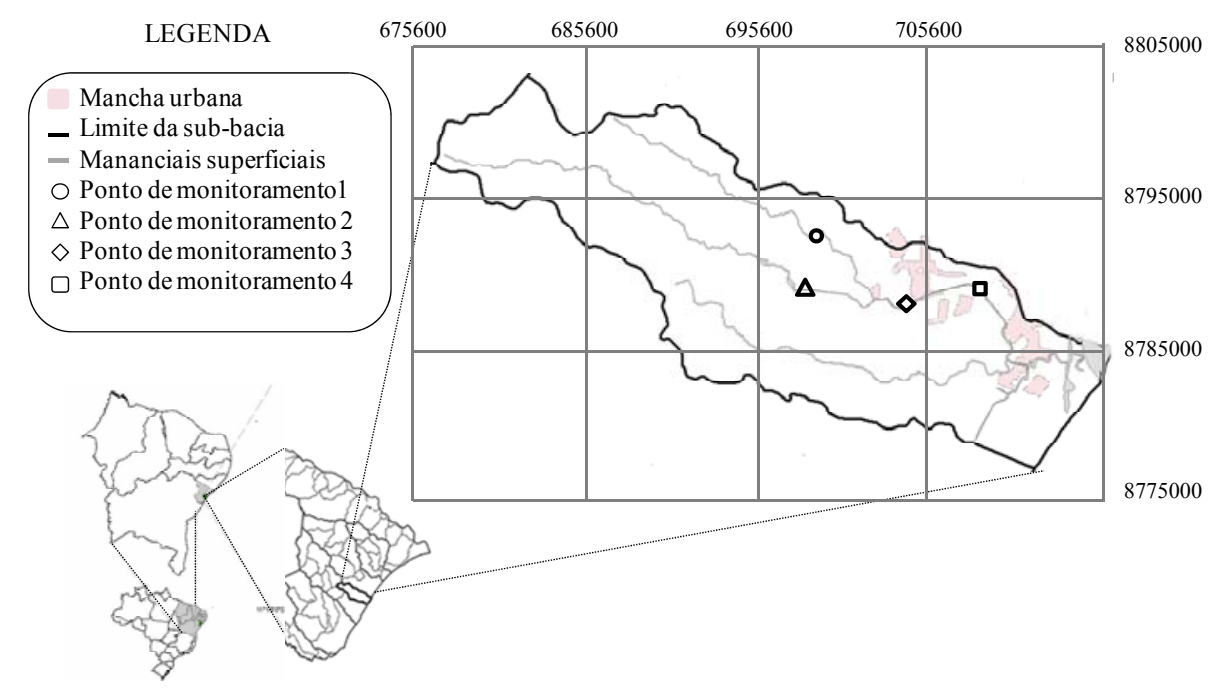

Figura 1. Localização dos pontos de coleta de amostra de água na Subbacia Hidrográfica do Rio Poxim em Sergipe. Fonte: Sergipe (2004).

Para obtenção da comunidade zooplanctônica foram filtrados $60 \mathrm{~L}$ da água do rio em uma tela de nylon, com aberturas de malha de $50 \mu \mathrm{m}$, com auxílio de um balde de plástico de capacidade de $20 \mathrm{~L}$. O material filtrado foi acondicionado em recipientes plásticos de $250 \mathrm{~mL}$ e preservados em solução $6: 3: 1$, que é equivalente a $60 \%$ de água destilada, $30 \%$ de álcool etílico e $10 \%$ de formaldeído. Logo após, foram adicionadas, a cada amostra, 5 gotas de sulfato de cobre a $10 \%$, com o objetivo de preservar a coloração dos organismos a serem analisados. Para análises quali-quantitativas, foram examinadas 46 amostras, com retirada de subamostras de $2 \mathrm{~mL}$ para contagem de indivíduos em câmara do tipo Sedgewick-Rafter e identificação em microscópio óptico, no menor nível taxonômico possível, utilizando-se bibliografias especializadas.

A frequência de ocorrência (Fo) das espécies identificadas foi calculada com base na relação do número de amostras em que o organismo ocorreu e o número total de amostras coletadas. Seguindo os critérios de Mateucci e Colma (1982), utilizou-se a fórmula $\mathrm{F}=$ Px100/p, sendo $\mathbf{P}$ o número de amostras contendo a espécie e $\mathbf{p}$ o número total de amostras coletadas. Foram consideradas as seguintes categorias de classificação: $\geq 70 \%$ muito frequente; $<70 \%$ a $\geq 40 \%$ frequente $;<40 \%$ a $\geq 10 \%$ pouco frequente $;<10 \%$ esporádico.

A abundância relativa dos diferentes organismos foi calculada levando-se em consideração o número de indivíduos da espécie por amostra analisada, em relação ao número total de indivíduos da amostra, expressa em percentual, foram atribuídos os critérios: $\geq 70 \%$ dominantes; $<70 \%$ a $\geq 40 \%$ abundante $;<40 \%$ a $\geq 10 \%$ pouco abundante $\mathrm{e}<10 \%$ rara (Lobo e Leighton, 1986).

Os índices de diversidade específica $\left(\mathrm{H}^{\prime}\right)$ das espécies analisadas basearam-se em Shannon (1948) e foram calculados mediante a fórmula: H' $=-\sum$ pi.Log2 pi. Em que: pi - ni / $\mathrm{N}$, ni - número de indivíduos de cada espécie; $\mathrm{N}$ - número total de indivíduos da amostra. $\mathrm{O}$ resultado foi expresso em bit. ind ${ }^{-1}$, considerando-se os seguintes critérios: $\geq 3,0$ bits.ind $^{-1}$ representa uma alta diversidade; $<3,0$ a $\geq 2,0$ bits.ind $^{-1}$ representa uma média diversidade; $<$ 2,0 a $\geq 1,0$ bits.ind $^{-1}$ representa uma baixa diversidade e $<1,0$ bits.ind $^{-1}$ representa uma diversidade muito baixa.

A equidade (J) foi calculada a partir do índice de Shannon (H' / H max.), pela fórmula de Pielou (1967): J = H' / Log S. Adotam-se, para esse índice, valores compreendidos entre 0 e $1, \mathrm{e}>0,5$ indica boa distribuição dos indivíduos entre as espécies. 


\section{RESULTADOS E DISCUSSÃO}

\subsection{Composição e riqueza de espécies}

A composição zooplanctônica da Sub-bacia do Rio Poxim esteve representada por Protozoa, Rotífera, Porífera, Nematoda, Anellida, Isopoda, Insecta e microcrustáceos das classes Cladocera, Copepoda e Ostracoda (Figura 2). Destes, Rotifera e Protozoa foram os grupos de maior representatividade, com 40 e 15 táxons respectivamente.

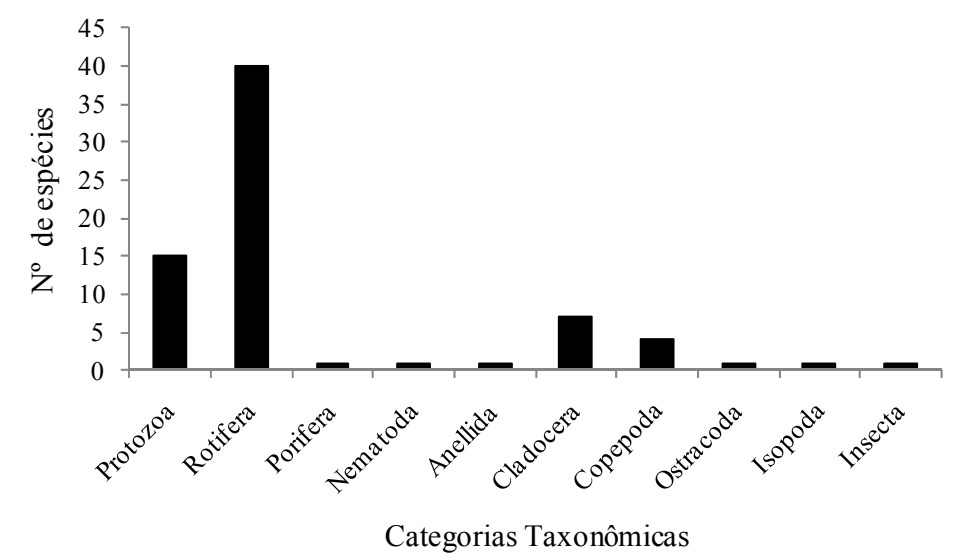

Figura 2. Composição zooplanctônica presente nos rios da Sub-bacia do Rio Poxim no período de agosto de 2009 a julho de 2010.

Em relação às categorias taxonômicas, houve predomínio do filo Rotífera, com valores que variaram de no máximo 32 táxons no Ponto de monitoramento P3 e mínimo de 21 táxons no Ponto 1, seguida dos Protozoa com valor máximo de 14 táxons no Ponto 1 e mínimo de 9 táxons no Ponto 2. Na classe dos Cladocera ocorreu um número máximo de 5 táxons identificados no Ponto 4 e um mínimo de 2 táxons no Ponto 2. Na classe Copepoda, observaram-se um máximo de 4 táxons nos Pontos 3 e 4 e um mínimo de 3 táxons nos Pontos 1 e 2. Nas classes Ostracoda, Isopoda e Insecta ocorreu apenas um táxon identificado nos Pontos 2, 3 e 4 (Ostracoda), Ponto 3 (Isopoda) e Pontos 2 e 3 (Insecta) (Figura 3).

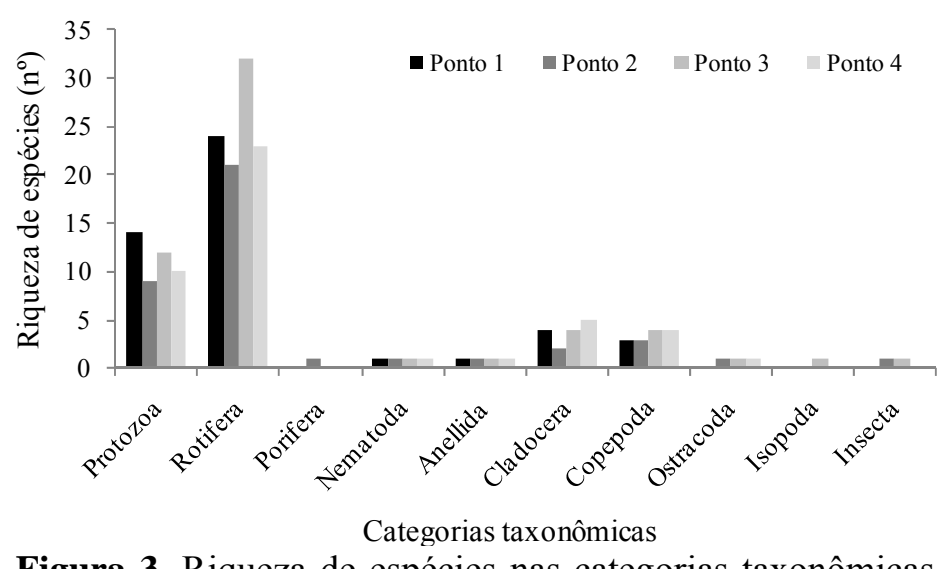

Figura 3. Riqueza de espécies nas categorias taxonômicas identificadas na Sub-bacia Hidrográfica do Rio Poxim, no período de agosto de 2009 a julho de 2010.

A composição zooplanctônica teve sua maior distribuição no período seco com 1143 organismos registrado nesse período, já no período chuvoso foram registrados 717 organismos (Figura 4), apresentando diferenças relevantes, evidenciando que no período entre 
setembro e março a comunidade zooplanctônica se estabelece com maior expressão. Esses valores, de certa forma, acompanharam as oscilações inversas aos índices pluviométricos (Figura 5). Provavelmente essa variável pode ter sido a principal causa pelos picos de abundância registrados para a comunidade zooplanctônica.

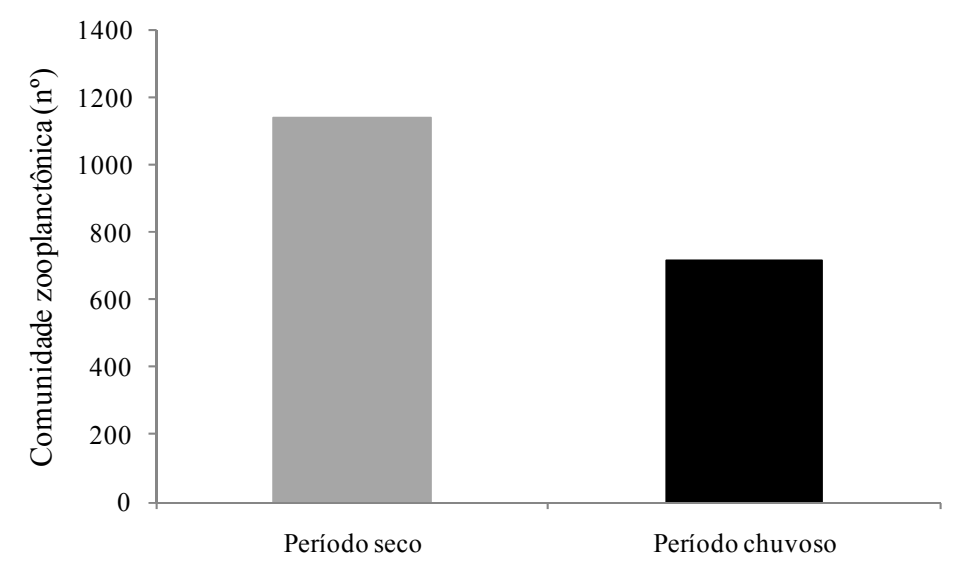

Figura 4. Composição zooplanctônica nos períodos (seco e chuvoso) na Sub-bacia Hidrográfica do Rio Poxim.

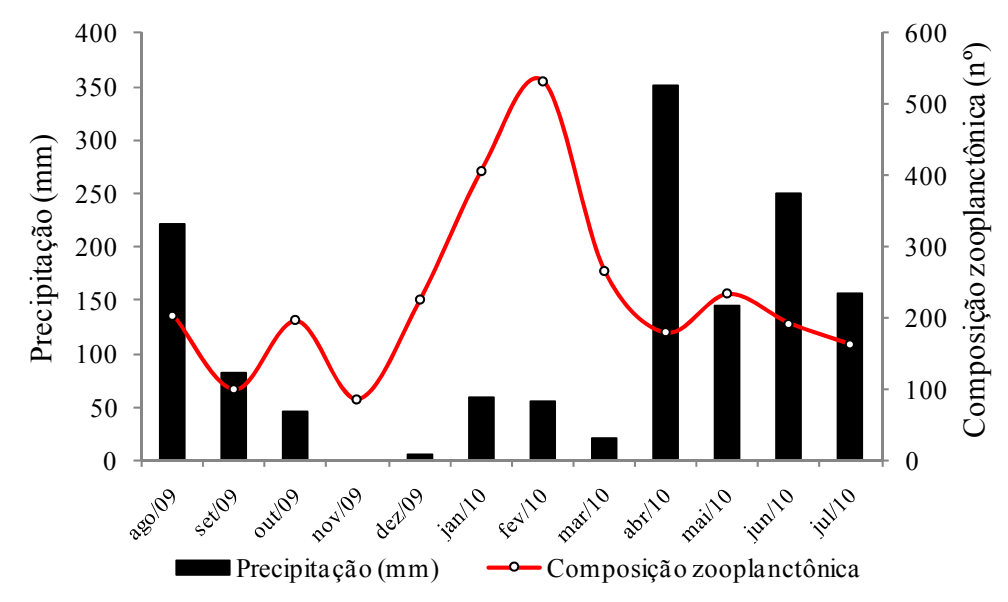

Figura 5. Relação entre a precipitação e a composição zooplanctônica identificada na Sub-bacia Hidrográfica do Rio Poxim, no período de agosto de 2009 a julho de 2010.

Nas regiões áridas ou semiáridas do Nordeste brasileiro as grandes variações de seus recursos hídricos, os baixos índices pluviométricos, bem como a elevada taxa de evaporação exercem importante papel na organização e funcionalidade dos ecossistemas aquáticos, em que as espécies presentes desenvolvem estratégias de sobrevivência, que acarretam em competições intra e interespecífica, assim como alterações na estrutura das comunidades e na disponibilidade de recursos naturais (Andreoli e Carneiro, 2005).

A dinâmica temporal registrada neste estudo também é observada em outros estudos brasileiros, apresentando menores densidades no período chuvoso e seco (Nogueira e Matsumura-Tundisi, 1996; Nogueira, 2001).

Em relação ao monitoramento temporal e espacial, verificou-se que, no mês de fevereiro de 2010, a composição zooplanctônica esteve com maior representatividade nas Estações 1 e 3. Por outro lado, as Estações 2 e 4 tiveram uma queda na sua distribuição (Figura 6). 


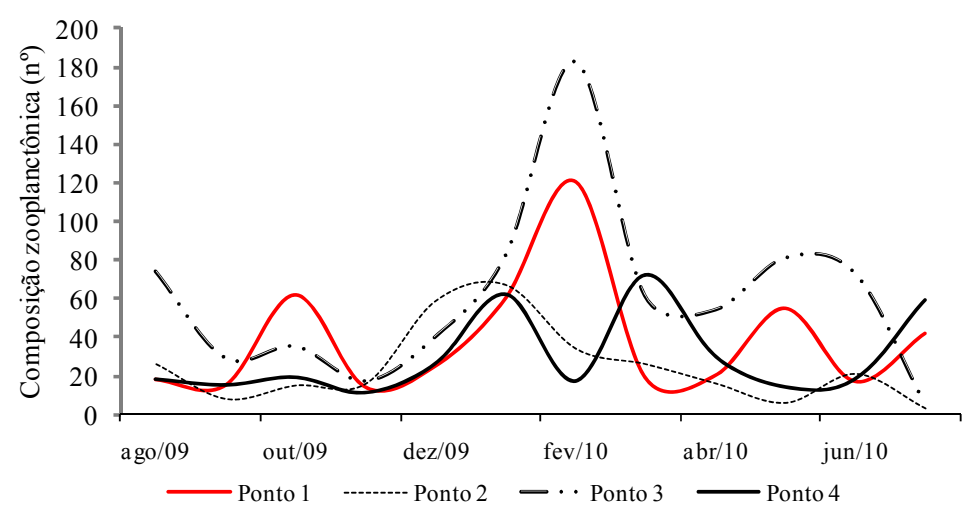

Figura 6. Variação espacial e temporal da composição Zooplanctônica da Sub-bacia do Rio Poxim, no período de agosto de 2009 a julho de 2010.

\subsection{Estrutura da comunidade zooplanctônica}

\subsubsection{Frequência de ocorrência}

No período de estudo dos 72 táxons identificados, nenhum foi classificado como muito frequente e frequente em todas as estações de coleta. Apenas as espécies Centropyxis acureata e Rotaria neptunia se apresentaram, respectivamente, como pouco frequente e esporádico em todas as estações. Centropyxis acureata é uma das espécies que apresentam maior distribuição geográfica no Brasil, encontrada em materiais planctônicos, sedimento e fauna associada às macrófitas aquáticas (Lansac-Tôha et al., 2000) (Tabela 1).

A frequência de 100\% para a espécie Polyarthra trigla nas Estações 3 e 4 indicam alto grau de estabilidade biológica (Bento, 2006). Chardez e Lambert (1981) considera que esse grupo de organismo possui grande poder de adaptação ao meio.

Outro aspecto a ser observado diz respeito à distribuição de algumas espécies que podem ser ocasionadas, principalmente pela velocidade da correnteza e concentração de material em suspensão na água (Panarelli et al., 2003).

Dentre as espécies de rotíferos registradas foi possível observar indicadoras de eutrofização e de poluição orgânica, a Rotaria sp., Lecane sp., K. cochlearis. Sendo esta última encontrada apenas no Ponto 3. Literatura pertinente configura-a como uma das espécies mais comum em águas continentais, sendo encontrada praticamente em todas as regiões biogeográficas.

No Ponto 1, dos 47 táxons identificados, 6,4\% das espécies foram classificadas como muito frequentes, $4,3 \%$ como frequentes, $31,9 \%$ como pouco frequentes e $57,4 \%$ como esporádicas. Destacando-se como muito frequentes: Notholca sp., Arcella vulgaris e Rotaria sp. No Ponto 2, dos 40 táxons identificados, 2,5\% das espécies foram classificadas como muito frequentes, $5 \%$ como frequentes, $32,5 \%$ como pouco frequentes e $60 \%$ como esporádicas. Destacando-se como muito frequente uma única espécie a Arcella vulgaris. No Ponto 3, dos 57 táxons identificados, $12,5 \%$ das espécies foram classificadas como muito frequentes, $3,6 \%$ como frequentes, $48,2 \%$ como pouco frequentes e $35,7 \%$ como esporádicas. Destacando-se como muito frequentes: Nematoda, Polyarthra trigla, Náuplios, Notholca sp., Difflugia limnetica, Arcella vulgaris e Asplanchna priodonta. 
PEREIRA, A. P. S.; VASCO, A. N. do; BRITTO, F. B.; MÉllo JÚNIOR, A. V.; NOGUEIRA, E. M. de S. Biodiversidade e estrutura da comunidade zooplanctônica na Sub-bacia Hidrográfica do Rio Poxim, Sergipe, Brasil.. Ambi-Agua, Taubaté, v. 6, n. 2, p. 191-205, 2011. (doi:10.4136/ambi-agua.194)

Tabela 1. Frequência de ocorrência dos táxons identificados na Sub-bacia Hidrográfica do Rio Poxim, no período de agosto de 2009 a julho de 2010.

\begin{tabular}{|c|c|c|c|c|}
\hline \multirow{2}{*}{ Táxon } & \multicolumn{3}{|c|}{ Pontos de coletas } & \multirow[b]{2}{*}{ P4 } \\
\hline & $\mathbf{P 1}$ & $\mathbf{P 2}$ & P3 & \\
\hline \multicolumn{5}{|l|}{ PROTOZOA } \\
\hline Arcella vulgaris & 245,7 & 152,2 & 287,0 & 65,2 \\
\hline Arcella gibosa & 4,4 & 6,5 & 13,0 & 0,0 \\
\hline Arcella dentata & 2,2 & 0,0 & 6,5 & 0,0 \\
\hline Centropyxis acureata & 23,9 & 32,6 & 37,0 & 15,2 \\
\hline Ciliata & 4,4 & 0,0 & 6,5 & 2,2 \\
\hline Euglypha acanthophora & 17,4 & 4,4 & 32,6 & 8,7 \\
\hline Euglypha sp. & 6,5 & 0,0 & 8,7 & 4,4 \\
\hline Diffugia corona & 2,2 & 0,0 & 0,0 & 10,9 \\
\hline Difflugia globulosa & 6,5 & 2,2 & 13,0 & 10,9 \\
\hline Difflugia limnetica & 10,9 & 30,4 & 87,0 & 45,7 \\
\hline Diffugia spiralis & 0,0 & 0,0 & 0,0 & 6,5 \\
\hline Difflugia sp. & 4,4 & 2,2 & 2,2 & 0,0 \\
\hline Globigerina bulloides & 4,4 & 0,0 & 0,0 & 0,0 \\
\hline Trinema $s p$ & 2,2 & 26,1 & 17,4 & 6,5 \\
\hline Vorticella sp & 8,7 & 8,7 & 10,9 & 0,0 \\
\hline \multicolumn{5}{|l|}{ ROTIFERA } \\
\hline Anuraeopsis fissa & 13,0 & 4,4 & 0,0 & 0,0 \\
\hline Asplanchna priodonta & 52,2 & 26,1 & 71,7 & 58,7 \\
\hline Asplanchna sp & 4,4 & 21,7 & 19,6 & 8,7 \\
\hline Brachionus angularis & 0,0 & 4,4 & 13,0 & 19,6 \\
\hline Brachionus caudatus & 0,0 & 6,5 & 6,5 & 0,0 \\
\hline Brachionus quadridentatus & 0,0 & 0,0 & 0,0 & 2,2 \\
\hline Brachionus sp. & 0,0 & 2,2 & 8,7 & 0,0 \\
\hline Colurella unicinata & 6,5 & 4,4 & 37,0 & 0,0 \\
\hline Colurella sp. & 21,7 & 6,5 & 0,0 & 0,0 \\
\hline Filinia longiseta & 4,4 & 0,0 & 17,4 & 13,0 \\
\hline Filinia sp. & 0,0 & 0,0 & 2,2 & 0,0 \\
\hline Keratella cochlearis & 0,0 & 0,0 & 6,5 & 0,0 \\
\hline Keratella sp. & 0,0 & 0,0 & 2,2 & 0,0 \\
\hline Lecane curvicornes & 0,0 & 0,0 & 4,4 & 0,0 \\
\hline Lecane lunaris & 2,2 & 10,9 & 21,7 & 0,0 \\
\hline Lecane papuana & 6,5 & 0,0 & 4,4 & 6,5 \\
\hline Lecane sp. & 21,7 & 10,9 & 13,0 & 17,4 \\
\hline Lecane sverigis & 6,5 & 0,0 & 15,2 & 10,9 \\
\hline Lepadella acuminata & 8,7 & 0,0 & 19,6 & 4,4 \\
\hline Lepadella latusinus & 0,0 & 0,0 & 4,4 & 0,0 \\
\hline Lepadella sp. & 10,9 & 0,0 & 2,2 & 0,0 \\
\hline Macrochaetus serica & 0,0 & 0,0 & 0,0 & 8,7 \\
\hline Monostyla arcuata & 19,6 & 19,6 & 19,6 & 17,4 \\
\hline Monostyla sp & 19,6 & 41,3 & 28,3 & 17,4 \\
\hline Mytilina bicarinata & 10,9 & 8,7 & 23,9 & 4,4 \\
\hline Mytilina sp. & 0,0 & 0,0 & 0,0 & 0,0 \\
\hline Notholca sp. & 152,2 & 52,2 & 71,7 & 2,2 \\
\hline Notommatidae & 0,0 & 0,0 & 0,0 & 2,2 \\
\hline Platyias quadricornis & 2,2 & 0,0 & 2,2 & 0,0 \\
\hline Polyarthra trigla & 8,7 & 10,9 & 100,0 & 100,0 \\
\hline Polyarthra sp. & 0,0 & 0,0 & 19,6 & 8,7 \\
\hline Polyathra vulgaris & 39,1 & 28,3 & 34,8 & 6,5 \\
\hline Rotaria rotatória & 6,5 & 0,0 & 45,7 & 0,0 \\
\hline Rotaria neptunia & 4,4 & 6,5 & 2,2 & 4,4 \\
\hline
\end{tabular}


PEREIRA, A. P. S.; VASCO, A. N. do; BRITTO, F. B.; MÉllO JÚNIOR, A. V.; NOGUEIRA, E. M. de S. Biodiversidade e estrutura da comunidade zooplanctônica na Sub-bacia Hidrográfica do Rio Poxim, Sergipe, Brasil.. Ambi-Agua, Taubaté, v. 6, n. 2, p. 191-205, 2011. (doi:10.4136/ambi-agua.194)

\begin{tabular}{|c|c|c|c|c|}
\hline Rotaria sp. & 110,9 & 4,4 & 8,7 & 6,5 \\
\hline Testudinella patina & 0,0 & 0,0 & 0,0 & 0,0 \\
\hline Trichocerca bicristata & 26,1 & 30,4 & 65,2 & 10,9 \\
\hline Trichocerca pusilla & 0,0 & 0,0 & 0,0 & 0,0 \\
\hline Trichocerca longiseta & 4,4 & 10,9 & 0,0 & 23,9 \\
\hline Trichocerca sp. & 0,0 & 8,7 & 19,6 & 17,4 \\
\hline \multicolumn{5}{|l|}{ PORIFERA } \\
\hline Espícula & 0,0 & 2,2 & 0,0 & 0,0 \\
\hline \multicolumn{5}{|l|}{ NEMATELMINTOS } \\
\hline Nematoda & 47,8 & 21,7 & 156,5 & 21,7 \\
\hline ANNELIDA & 0,0 & 0,0 & 0,0 & 0,0 \\
\hline Polychaeta & 23,9 & 8,7 & 19,6 & 4,4 \\
\hline \multicolumn{5}{|l|}{ CLADOCERA } \\
\hline Alona rectangula & 4,4 & 2,2 & 15,2 & 4,4 \\
\hline Alona sp. & 2,2 & 6,5 & 10,9 & 2,2 \\
\hline Bosmina longirostris & 2,2 & 0,0 & 2,2 & 2,2 \\
\hline Chydorus sphaericus & 0,0 & 0,0 & 0,0 & 2,2 \\
\hline Chydorus sp. & 0,0 & 0,0 & 0,0 & 4,4 \\
\hline Holopedium gibberum & 4,4 & 0,0 & 0,0 & 0,0 \\
\hline Moina dúbia & 0,0 & 0,0 & 10,9 & 0,0 \\
\hline \multicolumn{5}{|l|}{ COPEPODA } \\
\hline Copepoda & 10,9 & 4,4 & 28,3 & 8,7 \\
\hline Náuplios & 13,0 & 8,7 & 80,4 & 89,1 \\
\hline Paracyclops fimbriatus & 2,2 & 0,0 & 6,5 & 2,2 \\
\hline Thermocyclops decipiens & 0,0 & 2,2 & 15,2 & 15,2 \\
\hline \multicolumn{5}{|l|}{ OSTRACODA } \\
\hline Ostracoda & 0,0 & 2,2 & 15,2 & 8,7 \\
\hline \multicolumn{5}{|l|}{ ISOPODA } \\
\hline Isopoda & 0,0 & 0,0 & 2,2 & 0,0 \\
\hline \multicolumn{5}{|l|}{ INSECTA } \\
\hline Larva & 0,0 & 2,2 & 2,2 & 0,0 \\
\hline
\end{tabular}

Nota: $\geq 70$ Muito frequente, $<70 \geq 40$ frequente, $<40 \geq 10$ pouco frequente $\mathrm{e}<10$ esporádico.

O grupo nematoda é considerado como o mais rico em espécies e mais abundante na face da Terra, estima-se a existência de mais de um milhão de espécies e somente $1 \%$ está descrita. São encontrados como parasitos no interior de vegetais e animais vertebrados e invertebrados, e de vida livre em ambientes de água doce e marinha e na maioria dos ambientes terrestres podendo ser encontrados em todas as latitudes, graças a vários tipos de adaptações que lhes permite enfrentar desde o congelamento até o estresse hídrico. No presente estudo, esse grupo se mostrou muito frequente apenas no Ponto 3, onde o uso do Rio Poxim é bem antropizado sendo indicadores de ambientes eutrofizados.

No Ponto 4, dos 45 táxons identificados, 4,4\% das espécies foram classificadas como muito frequentes, $6,7 \%$ como frequentes, $31,1 \%$ como pouco frequentes e $57,8 \%$ como esporádicas. Destacando-se como muito frequentes: Polyarthra trigla e Náuplios.

\subsubsection{Abundância Relativa}

Durante o período de estudo dos 72 táxons identificados, apenas cinco $(6,9 \%)$ se apresentaram pouco abundantes e os demais foram considerados espécies raras $(93,1 \%)$. Destacando-se como pouco abundante a Arcella vulgaris nas Estações 1, 2 e 3, Notholca sp. no Ponto 1, Polyarthra trigla no ponto 4, Rotaria $s p$. No Ponto 1 e Náuplios no Ponto 4 (Tabela 2). 
PEREIRA, A. P. S.; VASCO, A. N. do; BRITTO, F. B.; MÉllo JÚNIOR, A. V.; NOGUEIRA, E. M. de S. Biodiversidade e estrutura da comunidade zooplanctônica na Sub-bacia Hidrográfica do Rio Poxim, Sergipe, Brasil.. Ambi-Agua, Taubaté, v. 6, n. 2, p. 191-205, 2011. (doi:10.4136/ambi-agua.194)

Tabela 2. Abundância relativa dos táxons identificados na Sub-bacia Hidrográfica do Rio Poxim, no período de agosto de 2009 a julho de 2010.

\begin{tabular}{|c|c|c|c|c|}
\hline \multirow{2}{*}{ Táxon } & \multicolumn{4}{|c|}{ Pontos de coletas } \\
\hline & P1 & $\mathbf{P} 2$ & $\mathbf{P 3}$ & P4 \\
\hline \multicolumn{5}{|l|}{ PROTOZOA } \\
\hline Arcella vulgaris & 24,2 & 23,6 & 18,0 & 9,2 \\
\hline Arcella gibosa & 0,4 & 1,0 & 0,8 & 0,0 \\
\hline Arcella dentata & 0,2 & 0,0 & 0,4 & 0,0 \\
\hline Centropyxis acureata & 2,4 & 5,1 & 2,3 & 2,1 \\
\hline Ciliata & 0,4 & 0,0 & 0,4 & 0,3 \\
\hline Euglypha acanthophora & 1,7 & 0.67 & 2,0 & 1,2 \\
\hline Euglypha sp. & 0,6 & 0,0 & 0,5 & 0,6 \\
\hline Diffugia corona & 0,2 & 0,0 & 0,0 & 1,5 \\
\hline Difflugia globulosa & 0,6 & 0,3 & 0,8 & 1,5 \\
\hline Difflugia limnetica & 1,1 & 4,7 & 5,4 & 6,4 \\
\hline Diffugia spiralis & 0,0 & 0,0 & 0,0 & 0,9 \\
\hline Difflugia sp. & 0,4 & 0,3 & 0,1 & 0,0 \\
\hline Globigerina bulloides & 0,4 & 0,0 & 0,0 & 0,0 \\
\hline Trinema sp & 0,2 & 4,0 & 1,1 & 0,9 \\
\hline Vorticella sp & 0,9 & 1,4 & 0,7 & 0,0 \\
\hline \multicolumn{5}{|l|}{ ROTIFERA } \\
\hline Anuraeopsis fissa & 1,3 & 0,7 & 0,0 & 0,0 \\
\hline Asplanchna priodonta & 5,1 & 4,0 & 4,5 & 8,2 \\
\hline Asplanchna sp & 0,4 & 3,4 & 1,2 & 1,2 \\
\hline Brachionus angularis & 0,0 & 0,7 & 0,8 & 2,7 \\
\hline Brachionus caudatus & 0,0 & 1,0 & 0,4 & 0,0 \\
\hline Brachionus quadridentatus & 0,0 & 0,0 & 0,0 & 0,3 \\
\hline Brachionus sp. & 0,0 & 0,3 & 0,5 & 0,0 \\
\hline Colurella unicinata & 0,6 & 0,7 & 2,3 & 0,0 \\
\hline Colurella sp. & 2,1 & 1,0 & 0,0 & 0,0 \\
\hline Filinia longiseta & 0,4 & 0,0 & 1,1 & 1,8 \\
\hline Filinia sp. & 0,0 & 0,0 & 0,1 & 0,0 \\
\hline Keratella cochlearis & 0,0 & 0,0 & 0,4 & 0,0 \\
\hline Keratella sp. & 0,0 & 0,0 & 0,1 & 0,0 \\
\hline Lecane curvicornes & 0,0 & 0,0 & 0,3 & 0,0 \\
\hline Lecane lunaris & 0,2 & 1,7 & 1,4 & 0,0 \\
\hline Lecane papuana & 0,6 & 0,0 & 0,3 & 0,9 \\
\hline Lecane sp. & 2,1 & 1,7 & 0,8 & 2,4 \\
\hline Lecane sverigis & 0,6 & 0,0 & 1,0 & 1,5 \\
\hline Lepadella acuminata & 0,9 & 0,0 & 1,2 & 0,6 \\
\hline Lepadella latusinus & 0,0 & 0,0 & 0,3 & 0,0 \\
\hline Lepadella sp. & 1,1 & 0,0 & 0,1 & 0,0 \\
\hline Macrochaetus sérica & 0,0 & 0,0 & 0,0 & 1,2 \\
\hline Monostyla arcuata & 1,9 & 3,0 & 1,2 & 2,4 \\
\hline Monostyla sp & 1,9 & 6,4 & 1,8 & 2,4 \\
\hline Mytilina bicarinata & 1,1 & 1,4 & 1,5 & 0,6 \\
\hline Mytilina sp. & 0,0 & 0,0 & 0,0 & 0,0 \\
\hline Notholca sp. & 15,0 & 8,1 & 4,5 & 0,3 \\
\hline Platyias quadricornis & 0,2 & 0,0 & 0,1 & 0,0 \\
\hline Polyarthra trigla & 0,9 & 1,7 & 6,3 & 14,0 \\
\hline Polyarthra sp. & 0,0 & 0,0 & 1,2 & 1,2 \\
\hline Polyathra vulgaris & 3,9 & 4,4 & 2,2 & 0,9 \\
\hline Rotaria rotatória & 0,6 & 0,0 & 2,9 & 0,0 \\
\hline Rotaria neptunia & 0,4 & 1,0 & 0,1 & 0,6 \\
\hline Rotaria sp. & 10,9 & 0,7 & 0,5 & 0,9 \\
\hline
\end{tabular}


PEREIRA, A. P. S.; VASCO, A. N. do; BRITTO, F. B.; MÉllo JÚNIOR, A. V.; NOGUEIRA, E. M. de S. Biodiversidade e estrutura da comunidade zooplanctônica na Sub-bacia Hidrográfica do Rio Poxim, Sergipe, Brasil.. Ambi-Agua, Taubaté, v. 6, n. 2, p. 191-205, 2011. (doi:10.4136/ambi-agua.194)

\begin{tabular}{|c|c|c|c|c|}
\hline Testudinella patina & 0,0 & 0,0 & 0,0 & 0,0 \\
\hline Trichocerca bicristata & 2,6 & 4,7 & 4,1 & 1,5 \\
\hline Trichocerca pusilla & 0,0 & 0,0 & 0,0 & 0,0 \\
\hline Trichocerca longiseta & 0,4 & 1,7 & 0,0 & 3,4 \\
\hline Trichocerca sp. & 0,0 & 1,4 & 1,2 & 2,4 \\
\hline \multicolumn{5}{|l|}{ PORIFERA } \\
\hline $\begin{array}{l}\text { Espícula } \\
\text { NEMATELMINTOS }\end{array}$ & 0,0 & 0,3 & 0,0 & 0,0 \\
\hline $\begin{array}{l}\text { Nematoda } \\
\text { ANNELIDA }\end{array}$ & 4,7 & 3,4 & 9,8 & 3,1 \\
\hline $\begin{array}{l}\text { Polychaeta } \\
\text { CLADOCERA }\end{array}$ & 2,4 & 1,4 & 1,2 & 0,6 \\
\hline Alona rectangula & 0,4 & 0,3 & 1,0 & 0,6 \\
\hline Alona sp. & 0,2 & 1,0 & 0,7 & 0,3 \\
\hline Bosmina longirostris & 0,2 & 0,0 & 0,1 & 0,3 \\
\hline Chydorus sphaericus & 0,0 & 0,0 & 0,0 & 0,3 \\
\hline Chydorus sp. & 0,0 & 0,0 & 0,0 & 0,6 \\
\hline Holopedium gibberum & 0,4 & 0,0 & 0,0 & 0,0 \\
\hline $\begin{array}{l}\text { Moina dúbia } \\
\text { COPEPODA }\end{array}$ & 0,0 & 0,0 & 0,7 & 0,0 \\
\hline Copepoda & 1,1 & 0,7 & 1,8 & 1,2 \\
\hline Náuplios & 1,3 & 1,4 & 5,0 & 12,5 \\
\hline Paracyclops fimbriatus & 0,2 & 0,0 & 0,4 & 0,3 \\
\hline Thermocyclops decipiens & 0,0 & 0,3 & 1,0 & 2,1 \\
\hline \multicolumn{5}{|l|}{ OSTRACODA } \\
\hline \multicolumn{2}{|l|}{ ISOPODA } & 0,3 & 1,0 & 1,2 \\
\hline $\begin{array}{l}\text { Isopoda } \\
\text { INSECTA }\end{array}$ & 0,0 & 0,0 & 0,1 & 0,0 \\
\hline Larva & 0,0 & 0,3 & 0,1 & 0,0 \\
\hline TOTAL & 100,0 & 100,0 & 100,0 & $\overline{100,0}$ \\
\hline
\end{tabular}

Nota: dominante: $\geq 70$, abundante: $<70 \geq 40$, pouco abundante: $<40 \geq 10$ e rara: $<10$.

\subsection{3. Índice de diversidade (H') e equitabilidade ( $\left.E^{\prime}\right)$}

A diversidade do zooplâncton na Sub-bacia do Rio Poxim foi avaliada pela índice de Shannon-Wiener, que leva em consideração a riqueza e abundância das espécies. Pinto Coelho et al. (1999) verificam os efeitos da eutrofização na estrutura das comunidades planctônicas no reservatório da Pampulha em Belo Horizonte, utilizando diferentes índices de diversidade, os resultados obtidos mostraram que o Índice de Shannon foi mais adequado para estudos de comunidades mais eficientemente amostradas.

No estudo, os valores de diversidade foram similares entre os pontos de amostragem, sendo registrado o maior valor no Ponto 2 com 2,1 bits.ind $^{-1}$ sendo caracterizada como média diversidade e a menor no Ponto 1 com 1,8 bits.ind ${ }^{-1}$, caracterizada como baixa diversidade. A distribuição (equidade) dos táxons nos pontos e nos meses amostrados manteve-se uniforme, visto que os valores obtidos para esse dado estiveram acima de 0,5 (Figura 7).

Em relação à dinâmica temporal, a diversidade apresentou um padrão heterogêneo, registrando maiores flutuações nos meses de Setembro/09, Março, Maio e Julho/10 (período chuvoso) com valores de 2,1; 2; 2,2 e 2,3 bits.ind $^{-1}$ caracterizando-se como média diversidade. Nos outros meses foram registrados valores abaixo de 2, sendo caracterizado como baixa diversidade. 
PEREIRA, A. P. S.; VASCO, A. N. do; BRITTO, F. B.; MÉllo JÚNIOR, A. V.; NOGUEIRA, E. M. de S. Biodiversidade e estrutura da comunidade zooplanctônica na Sub-bacia Hidrográfica do Rio Poxim, Sergipe, Brasil.. Ambi-Agua, Taubaté, v. 6, n. 2, p. 191-205, 2011. (doi:10.4136/ambi-agua.194)

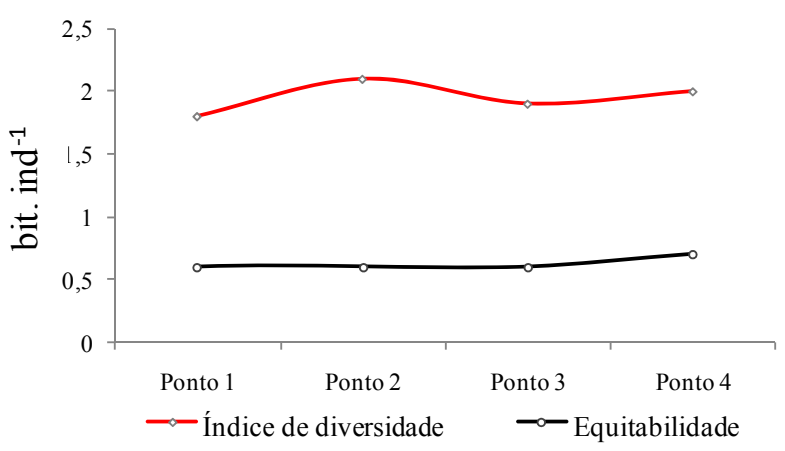

A

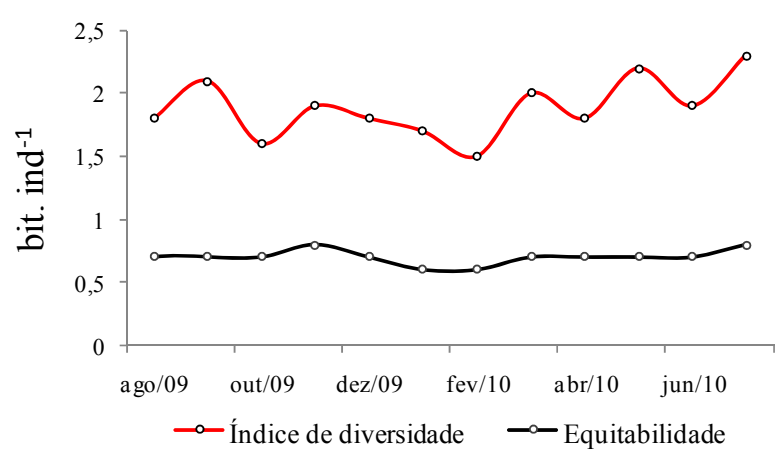

B

Figura 7. Diversidade e equitabilidade espacial (A) e temporal (B) da comunidade zooplanctônica da Sub-bacia do Rio Poxim, no período de agosto de 2009 a julho de 2010.

Esteves (1998) considera que o zooplâncton de água doce está caracterizado pela baixa diversidade. Em ambientes límnicos, isso ocorre pelo reduzido número de espécies e maior densidade de indivíduos, quando comparados aos ecossistemas marinhos.

Em ambientes pequenos e lênticos, as variações ambientais são mais acentuadas, o que pode ocasionar o domínio de determinadas espécies e diminuição, ou até mesmo exclusão, de outras. Isso acarreta o número reduzido de espécies e, em contrapartida, alta densidade de indivíduos (Tavares, 1994). No entanto, a diversidade também está relacionada com a competição e a predação. A competição por recursos limitados tem sido considerada o determinante primário na diversidade de espécies, pois, à medida que os recursos se tornam escassos, somente os mais eficientes prevalecem, resultando em um menor número de espécies (Giller, 1984).

A relação entre a diversidade de espécies (riqueza e equitabilidade) e a estabilidade de um ecossistema é complexa, uma vez que ecossistemas estáveis promovem uma alta diversidade, mas o contrário não é necessariamente verdadeiro. Portanto, mesmo que os valores de diversidade tenham sido de média a baixa, várias explicações podem ser consideradas, principalmente no tocante ao tempo de coleta e a dinâmica da bacia hidrográfica.

São várias as hipóteses para se explicar a alta diversidade nos diferentes ecossistemas. A mais aceita é aquela que considera a estabilidade ambiental como a causa de alta diversidade, levando em consideração que o ambiente tropical sendo influenciado por clima mais favorável, permite a especialização e evolução de muitas espécies e isso favorece aquelas que têm alta probabilidade de extinção nesses ambientes, dando origem a uma grande quantidade de espécies raras na comunidade (Giller, 1984).

Muitos estudos têm demonstrado que os habitat de regiões tropicais suportam maiores números de espécies do que em regiões temperadas. Sob esse aspecto nas comunidades planctônicas existem ainda muitas incertezas acerca dessa informação, pois os dados de regiões tropicais são muito insuficiente, tanto na análise taxonômica dos grupos, como na exploração dos diversos corpos d'água (Lansac-Tôha et al., 2000).

\section{CONCLUSÃO}

A comunidade zooplanctônica da Sub-bacia Hidrográfica do Rio Poxim no Estado de Sergipe apresentou uma composição específica comum aos inventários realizados no nordeste, não sendo observado nenhum registro novo para a área.

A predominância de rotíferos já é esperada para ambientes continentais, representando mais de $60 \%$ do total da comunidade zooplanctônica, independente do estado trófíco das águas, embora muitas espécies do grupo sejam utilizadas como indicadoras de qualidade 
PEREIRA, A. P. S.; VASCO, A. N. do; BRITTO, F. B.; MÉllo JÚNIOR, A. V.; NOGUEIRA, E. M. de S. Biodiversidade e estrutura da comunidade zooplanctônica na Sub-bacia Hidrográfica do Rio Poxim, Sergipe, Brasil.. Ambi-Agua, Taubaté, v. 6, n. 2, p. 191-205, 2011. (doi:10.4136/ambi-agua.194)

ambiental, a exemplo dos gêneros Rotaria, Brachionus, Keratella, Platyias e Lecane. Todas as espécies citadas foram registradas no presente estudo.

Os rotíferos constituem a maior parte do zooplâncton de água doce, visto que são organismos oportunistas e de fácil adaptação às mudanças das condições ambientais, além do tempo de geração ser mais curto que os outros organismos do plâncton. Na área estudada foram os mais expressivos em riqueza de espécies, no entanto, não apresentaram grandes abundâncias.

Os protoctistas tiveram maior representatividade pelo grupo das tecamebas e os táxons que melhor se representaram foram a Arcella vulgaris, Centropyxis acureata e Difflugia limnetica, as quais são comuns em inventários realizados em ecossistemas aquáticos continentais brasileiros.

Os crustáceos foram representados por cladóceros e copépodes. Para cladóceros houve a predominância de Alona rectangula, Alona sp. e Moina dubia, táxons considerados de ampla distribuição em águas tropicais e bons indicadores de trofia. O último apresenta-se também adaptado a ambientes com elevada concentração de compostos húmicos, baixa condutividade e $\mathrm{pH}$; sendo identificada apenas no ponto 3 , é indicadora de ambientes mesotróficos e oligotróficos. Os copépodes foram representados por duas espécies, em que Thermocyclops decipiens se apresentou pouco frequente nos Pontos 3 e 4, porém não foi abundante e nem teve densidades elevadas em nenhuma dos pontos monitorados. $\mathrm{O}$ pequeno número de espécies registrado para o grupo, em águas doces, é tido como um padrão.

Verificou-se a presença de nematódeos o que indica ambientes com certo grau e poluição, no entanto, sendo raro e esporádico para o período.

Os valores de diversidade e uniformidade revelaram que, para a área, a comunidade zooplanctônica constituiu-se em um grupo com baixa diversidade de espécies. A distribuição (equidade) dos táxons nas estações e nos meses amostrados manteve-se uniforme. Como poucas espécies apresentaram moderada dominância, o alto número de espécies raras e esporádicas teve uma maior importância para a redução dos valores de diversidade.

Devido ao relevante papel desempenhado dos zooplânctons no ambiente e a escassez de trabalhos realizados no nordeste, especialmente em Sergipe, há necessidade que novos estudos sejam desenvolvidos, com ampliação dos habitats de ocorrência do grupo, espacial e temporalmente.

\section{AGRADECIMENTOS}

À Fundação de Apoio à Pesquisa e à Inovação Tecnológica do Estado de Sergipe FAPITEC/SE, pelo apoio no financiamento do projeto de pesquisa.

\section{REFERÊNCIAS BIBLIOGRÁFICAS}

\section{ANDREOLI, C. V.; CARNEIRO, C. Gestão integrada de mananciais de abastecimento eutrofizados. Curitiba: Sanepar/ FINEP, 2005. 500p.}

BENTO, A. P. et al. Caracterização da microfauna em estação de tratamento de esgotos do tipo lodos ativados: um instrumento de avaliação e controle do processo. Eng. sanit. Ambient., v. 10, n. 4, p. 329-338, out./dez. 2005. Disponível em: $<$ http://www.scielo.br/pdf/esa/v10n4/a09v10n4.pdf>. Acesso em: 12 dez. 2006.

CHARDEZ, D.; LAMBERT, J. Tecamoebiens indicateurs biologiques (Protozoa, Rhizopoda, testacea). Bull. Rech. Agron. Gembloux, v. 16, n. 3, p. 181- 204, 1981.

ESTEVES, F. A. Fundamentos de limnologia. Rio de Janeiro: Interciência/FINEP, 1998. $574 \mathrm{p}$. 
PEREIRA, A. P. S.; VASCO, A. N. do; BRITTO, F. B.; MÉllo JÚNIOR, A. V.; NOGUEIRA, E. M. de S. Biodiversidade e estrutura da comunidade zooplanctônica na Sub-bacia Hidrográfica do Rio Poxim, Sergipe, Brasil.. Ambi-Agua, Taubaté, v. 6, n. 2, p. 191-205, 2011. (doi:10.4136/ambi-agua.194)

GILLER, P. S. Community structure and the niche. In: DUNNET, G. M.; GIMINGHAM, C. H. (Eds.). Outline studies in ecology. London: Chapman and Hall, 1984. 176p.

GILRON, G. L.; LYNN, D. H. Ciliated protozoa as test organisms in toxicity assessments. In: WELLS, P. G.; LEE, K.; BLAISE, C. (Eds.). Microscale testing in aquatic toxicology: advances, techniques, and practice. Boca Raton: CRC Press, 1997. p. 323-336.

LAMPERT, W. Laboratory studies on zooplankton-cyanobacteria interactions. New Zealand j. mar. freshw. res.., v. 21, n. 3, p. 483-490, 1987.

LANSAC-TÔHA, F. A. et al. On the occurrence of testate amoebae (Protozoa, Rhizopoda) in Brazilian inland waters. I. Family Arcellidae. Acta Scientiarum, Maringá, v. 22, n. 2 , p. 355-363, 2000.

LOBO, E.; LEIGHTON, G. Estructuras comunitarias de las fitocenosis planctónicas de los sistemas de desembocaduras de ríos y esteros de la zona central de Chile. Revista Biología Marina, v. 22, n. 1, p. 1-29, 1986.

MATEUCCI, S. D.; COLMA, A. Metodología para el estudio de la vegetación.Washington, DC: OEA, 1982. p. 1-168. (Série de biologia, 22).

MATSUMARA-TUNDISI, T.; TUNDISI, J. G. Calanoida (Copepoda) species composition changes in the reservoirs of São Paulo State (Brazil) in the last twenty years. Hidrobiologia, v. 504, n. 1/3, p. 215-222, 2003.

http://dx.doi.org/10.1023/B:HYDR.0000008521.43711.35

NOGRADY, T. Rotifera: biology, ecology and systematics. Haia: SPB Academic Publishing, 1993. vol. 1. 142p.

NOGUEIRA, M. G. Zooplankton composition, dominance and abundance as indicators of environmental comportmentalization in Jurumirim Resevoir (Paranapanema River), São Paulo, Brazil. Hidrobiologia, v. 455, n. 1, p. 1-18, 2001.

http://dx.doi.org/10.1023/A:1011946708757

NOGUEIRA, M. G.; MATSUMURA-TUNDISI, T. Limnologia de um sistema artificial raso (represa do Monjolinho-São Carlos-SP). Dinamica das populações planctônicas. Acta Limnol. Bras., v. 8, p 149-168, 1996.

PANARELLI, E. et al. A comunidade zooplanctônica ao longo de gradientes longitudinais no Rio Paranapanema/ Represa de Jurumirim (São Paulo, Brasil). In: HENRY, R. (Ed.). Ecótonos nas interfaces dos ecossistemas aquáticos. São Carlos: Rima, 2003. p. 129160.

PINTO-COELHO, R. M.; COELHO, M. M.; ESPÍRITO SANTO, M. M.; CORNELISSEN, T. G. Efeitos da eutrofização da comunidade planctônica na Lagoa de Pampulha, Belo Horizonte - MG. P. 551-572. In: HENRY, R. (Ed.). Ecologia de reservatório: estrutura, função e aspectos sociais. Botucatu: FUNDIBIO/FAPESB, 1999.

SAMPAIO, E. V.; ROCHA, O.; MATSUMURA-TUNDISI, T.; TUNDISI, J. G. Composition and abundance of zooplankton in the limnetic of Seven Reservoirs of the Paranapanema River. Brazilian Journal of Biology, v.62, n. 3, p. 525-545, 2002.

http://dx.doi.org/10.1590/S1519-69842002000300018

SANDERS, R. W.; WICKHAM, S. A. Planktonic protozoa and metazoan: predations, food quality and population control. Mar. Microb. Food Webs, v. 7, n. 2, p. 197-223, 1993. 
SERAFIM JR., M. Efeitos do represamento em um trecho do médio rio Iguaçu sobre a estrutura e dinâmica da comunidade zooplanctônica. 2002. 51f. Tese (Doutorado em Ecologia de Ambientes Aquáticos Continentais) - Universidade Estadual de Maringá, Maringá, 2002.

SERGIPE. Superintendência de Recursos Hídricos. Atlas digital sobre os recursos hídricos de Sergipe. Aracajú: SEPLANTEC-SRH, 2004. 1 CD-ROM.

SHANNON, C. E. A mathematical theory of communication. Bell System Technical Journal, San Diego, California, v.27, p. 379-423, 1948.

SIPAÚBA-TAVARES, L. H.; ROCHA, O. Produção de plâncton (fitoplancton e zooplancton) para alimentação de organismos aquáticos. 3. ed. São Carlos: Rima, 2001. 106p.

STEMBERGER, R. S.; GILBERT, J. J. Defenses of planktonic rotifers against predators. In: KERFOOT, W. C.; SIH, A. Predation. Hanover: University Press of New England, 1987. p. 227-239.

TAVARES, L. H. S. Limnologia aplicada a aqüicultura. Jaboticabal: FUNEP, 1994. 